\title{
The moon turns and we must turn with it: Te Maramataka as interactive art installation
}

\author{
Keywords \\ Intercultural hyphen; Rangahau; Emergent; Maramataka; Relational.
}

Intercultural collaborations between Te Ao Māori and Te Ao Pākehā are notoriously difficult for all concerned. What knowledge is and is not, who or what has agency in the world, how and when things happen, and the nature of relationships themselves, are situated within different culturally informed worldviews. Attempting to make a repository of knowledge about Te Maramataka (lunar calendar) through an immersive interactive artwork, means engaging with two distinctively different, but equally valid, knowledge frameworks and their attendant foundational metaphysics. Navigating between and through these knowledge frameworks is to participate in speculative and practice-led approaches that foster relationally emergent phenomena. It is through collaboration at the intercultural hyphen that we deliberately walk into the innovation space, whilst also attempting to be mindful of upholding the mana of existing experts. At present, we represent a partnership between Te Rūnanga o Kirikiriroa and Wintec rangahau and creative arts research practitioners, each with our own institutionally informed accountabilities. By acknowledging ourselves as a collective rōpū (group) embarking on a shared endeavour, we can place emphasis in the process of learning about our shared whanaungatanga (interconnected relationships) in order to seek mutually acceptable agreements grounded in the useful. This emphasis on process is critical and must take its own time, particularly when Te Maramataka emphasises the influences of the turning moon phases on our own selves, as well as on everything else that is also already going on. In practice, agreeing that that the knowledge of Maramataka experts is situated, embodied and relational within the life context is easy to say, but should the modes of the finished work and the approach itself be representational and/ or epistemological? Or if we acknowledge the relationality between things, then we must also acknowledge that knowledge itself is experiential, embodied, and performative - in other words, how we 'get there' is part of the destination 'there' itself. In the context of deciding which digital technologies to employ in the making of an interactive art installation, contemporary understandings of what art is, how meaning is made and understood, and who or what has agency within the surrounding field of relations, are destabilised. In our practice-led undertaking, turning with the moon means acknowledging the dynamic tensions that exist between tradition with innovation, representation with experiential learning, and the knowable with the hidden, mysterious, and ultimately unknowable. Whether we are talking about rules-based claims of indexicality vis-à-vis digital twins informed by cognitivist frameworks of operational logics, or stateless open-ended $\mathrm{Al} /$ pattern recognition paradigms, these must be balanced against the existing knowledge of Maramataka Māori experts and their live, embodied knowledge. 